\title{
The treatment process of an extremely rare giant borderline phyllodes tumor of breast: case report and literature review
}

\author{
Qing Wang" ${ }^{1 \#}$, Kai Zheng ${ }^{1 \#}$, Lei Zhang ${ }^{1 \#}$, Mingjian Tan ${ }^{1}$, Hongwan Li $^{1}$, Hengyu Zhang ${ }^{1}$, Dong Chen ${ }^{2}$, \\ Zhilin $\mathrm{Li}^{3}$, Zhirui Chuan ${ }^{2}$, Xi Wang', Yuanxiao Wang ${ }^{1}$, Lei Zhe ${ }^{1}$, Lijuan Liu ${ }^{1}$, Dequan Liu ${ }^{1}$, Rong Guo ${ }^{1}$, \\ Shicong Tang ${ }^{1}$
}

${ }^{1}$ Department of Breast Surgery, the Third Affiliated Hospital of Kunming Medical University, Yunnan Cancer Hospital, Kunming, China; ${ }^{2}$ Department of Ultrasound, the Third Affiliated Hospital of Kunming Medical University, Yunnan Cancer Hospital, Kunming, China; ${ }^{3}$ Department of Radiology, the Third Affiliated Hospital of Kunming Medical University, Yunnan Cancer Hospital, Kunming, China

\#These authors contributed equally to this work.

Correspondence to: Dequan Liu; Rong Guo; Shicong Tang. Department of Breast Surgery, the Third Affiliated Hospital of Kunming Medical University, Yunnan Cancer Hospital, Kunming, China. Email: liu_dequan2018@126.com; guorong2320@126.com; tang_shicong@126.com.

\begin{abstract}
Giant phyllodes tumors are rare fibroepithelial neoplasms, usually defined as $>10 \mathrm{~cm}$. It is often difficult for pathologists to distinguish fibroadenomas from phyllodes tumors and determine the malignant potential level. The current treatment principle is to ensure the extended resection of tumors with a margin of $1 \mathrm{~cm}$ or more. For patients with multiple local recurrences or large tumors after surgery, simple mastectomy is recommended. Axillary management should be considered when breast cancer is diagnosed at the same time. We now present a rare case: a female patient found a right breast mass in 2014, and the mass had continued to grow for more than 7 months, and she was ultimately diagnosed with a giant phyllodes tumor with a diameter of $30 \mathrm{~cm}$. Extensive resection is a suitable method to treat smaller phyllodes tumors, but giant phyllodes tumors require mastectomy, so the patient in this case underwent a total mastectomy. We removed the mass completely without destroying the normal tissue and structure. The treatment effect was obvious, and no related adverse events occurred during or after the operation, the postoperative recovery was good, and the patient was discharged once she was verified to be in a stable condition. This case is the first reported case of a patient who had a giant borderline phyllodes tumor with a diameter of $30 \mathrm{~cm}$, underwent total mastectomy, and was followed up for 6 months without recurrence. The long-term effect of the treatment will be further evaluated after 5 years.
\end{abstract}

Keywords: Breast cancer; giant borderline phyllodes tumors; surgery; case report

Submitted Dec 18, 2020. Accepted for publication Mar 05, 2021.

doi: $10.21037 /$ tcr-20-3461

View this article at: http://dx.doi.org/10.21037/tcr-20-3461

\section{Introduction}

Phyllodes tumors of the breast are extremely rare, accounting for less than $1 \%$ of all primary breast tumors. The World Health Organization (WHO) classification of tumors recommends standards for the diagnosis and grading of phyllodes tumors. According to the tumor's mesenchymal cell density, cell heterogeneity, nuclear division, and tumor margins, it is divided into three levels: benign, borderline, and malignant (1). In the literature, the recurrence rates of benign, borderline, and malignant phyllodes tumors are $10-17 \%$,
$14-25 \%$, and $23-30 \%$, respectively, while $9 \%$ of malignant tumors are mainly metastases in the lung and bone (2) .

When we diagnose phyllodes tumors, the low limit of the abundance of mesenchymal cells is difficult to determine, but there must be a wide range of mesenchymal cells or accompanied by phyllodes structure to be diagnosed as benign phyllodes tumor diagnosis $(3,4)$. Malignant phyllodes tumors have the following characteristics: interstitial cell nucleus is obviously pleomorphic, the mesenchyme is overgrown so that only mesenchyme but 
no epithelial components are seen under a low-power field of view, the mitotic image is increased $[\geq 10 / 10$ high power field (HPF)], the interstitial cell is diffusely increased, and there is a tumor invasion boundary etc. Diagnosed as malignant phyllodes tumor. When the phyllodes tumor does not have all the malignant histological characteristics of malignant phyllodes tumors, then it is diagnosed as a benign phyllodes tumor $(5,6)$.

Regarding the surgical operation of phyllodes tumors, how wide should the margin be when removing borderline or malignant phyllodes tumors? Current National Comprehensive Cancer Network (NCCN) guidelines recommend resection to obtain surgical margins greater than $1 \mathrm{~cm}(7)$.

Due to the high recurrence rate, adjuvant radiotherapy as an improvement in local control has increased in the past few decades $(8,9)$. In the only prospective study published so far, Mitus et al. described the local control rate of marginally negative breast-conserving surgery and adjuvant radiotherapy for malignant and borderline phyllodes tumors $(10,11)$. Several retrospective studies have also proved the improvement of local control rate, but the results are inconsistent, and the indications of adjuvant local treatment are still controversial (12). Due to the rarity of the disease, especially the low number of malignant and borderline subtypes, randomized controlled trials have not been conducted, and it is still uncertain how to best treat it.

In this report, the patient had a rare giant borderline phyllodes tumor with a diameter of $30 \mathrm{~cm}$, and she had lived with the tumor for more than five years before he came to our hospital for treatment. When she came to the hospital, the tumor had ruptured and looked like a crater. The area of the ulcer was about " $5.0 \mathrm{~cm} \times 6.0 \mathrm{~cm} \times 5.0 \mathrm{~cm}$," and bloody fluid was constantly flowing out from the rupture point. We present the following case in accordance with the CARE reporting checklist (available at http://dx.doi.org/10.21037/ tcr-20-3461).

\section{Case presentation}

We report a case-a 47 -year-old female patient's chief complaint was that the right breast mass was found for more than 5 years ago, and the mass continued to increase for more than 7 months. She came to our hospital on April 20, 2020. In 2015, the patient found a right breast mass without obvious cause, no breast pain, nipple discharge, ulceration, redness, swelling, fever. No treatment was given, and regular re-examinations showed that the mass did not increase significantly. In August 2019, the patient felt that the lumps were larger than before, and the selfadministered medication (unknown) did not improve the condition. For further treatment, she went to a hospital and underwent B-ultrasound, to display right breast mid-low echo mass (BI-RADS:4A). It was recommended to undergo further treatment after breast mass puncture was confirmed, and the patient refused treatment. In the 3 months before the patient ultimately sought treatment, the patient felt that the swelling was significantly enlarged compared with before, accompanied by breast pain, with paroxysmal pain, breast ulceration, and bloody fluid outflow. The patient had no cold or fever. The patient has no family history of tumor. The study was approved by the People's committee of the Third Affiliated Hospital of Kunming Medical University (NO.: KY2019131). All procedures performed in studies involving human participants were in accordance with the ethical standards of the institutional and/or national research committee(s) and with the Declaration of Helsinki (as revised in 2013). Written informed consent was obtained from the patient.

\section{Physical examination}

The size of both breasts is obviously asymmetrical, and the right breast has a huge mass of about $30 \mathrm{~cm} \times 25 \mathrm{~cm} \times 25 \mathrm{~cm}$, with hard texture, unclear borders, poor mobility, and rupture, which looks like a crater. The ulcer area is about " $7.0 \mathrm{~cm} \times$ $7.0 \mathrm{~cm}$ ", and bloody fluid flows out from there, accompanied by skin adhesions (Figure 1). No enlarged lymph nodes were palpable on both sides of the axilla and clavicle. The head, neck, lungs, abdomen, and other physical examinations showed no obvious abnormalities (Figure 1).

\section{Auxiliary examination}

Blood test: Perform blood routine, liver and kidney function, tumor markers and other examinations, Table 1 for obvious abnormalities, and no obvious abnormalities for the rest. Breast B-ultrasound examination and radiography showed that the right breast had abnormal morphology and increased volume, and no normal gland echo was detected in it. Instead, multiple images of fusion masses were replaced. The nature of the tumor was investigated. BI-RADS:4C, consider malignant, (Figure 2A,B). The CT examination of the chest and abdomen showed that the right breast was huge, and the possibility of malignancy should be considered. The anterior and lower edge of the lesion was ruptured; the rest had no 

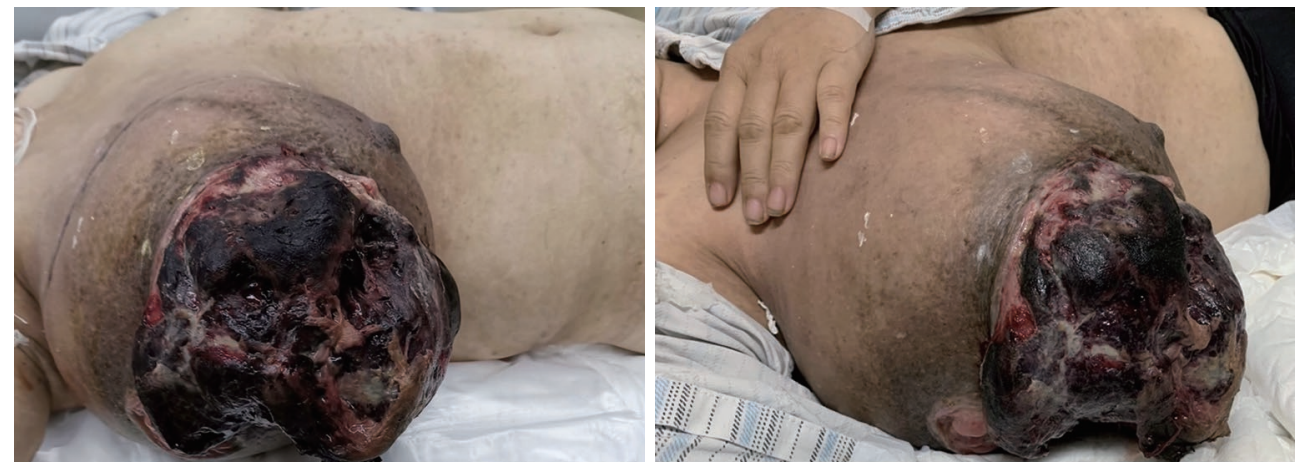

Figure 1 The patient's right breast tumor at the time of admission.

Table 1 Blood test

\begin{tabular}{|c|c|c|c|c|}
\hline Date & WBC $\left(10^{9} / \mathrm{L}\right)$ & $\mathrm{HB}(\mathrm{g} / \mathrm{L})$ & TP (g/L) & ALB (g/L) \\
\hline Apr. 20. 2020 & 10.88 & 75 & 53 & 31 \\
\hline Apr. 22. 2020 & 14.88 & 72 & 48 & 27 \\
\hline Apr. 23. 2020 & 16.48 & 95 & 50 & 31 \\
\hline Apr. 28. 2020 & 6.33 & 115 & 51 & 31 \\
\hline
\end{tabular}

WBC, leukocyte; HB, Hemoglobin; ALB, albumin.

obvious abnormalities (Figure 2C).

\section{Admission diagnosis}

A huge mass on the right breast. The patient's right breast mass had increased rapidly in a short period of time and was huge in size upon admission, with a diameter of $30 \mathrm{~cm}$. The patient was 47 years old. When the patient was admitted to the hospital, the mass was already very large and ruptured, so mammography and MRI examinations could not be performed, and the patient was unwilling to perform core needle biopsy; only breast B-ultrasound could be performed and showed the right breast is abnormal in shape and enlarged in size, and multiple images of fusion masses can be seen in it. Based on the patient's medical history, physical examination, and auxiliary examinations, we consider that it may be a phyllodes tumor. However, phyllodes tumors and fibroadenoma are both fibroepithelial tumors. They are very similar in clinical manifestations and imaging features, and need to be carefully differentiated. Therefore, the diagnosis still needs surgical complete resection and pathological biopsy.

\section{Systemic treatment process}

Because blood sampling of the patient was admitted to the hospital for blood sampling, considering moderate anemia and hypoproteinemia, on 2020-04-22, the day before her operation, she was given 5.0 U suspended red blood cells + $200 \mathrm{~mL}$ plasma intravenous infusion, and $6.0 \mathrm{U}$ suspended red blood cells were given via intravenous infusion during the operation. On 2020-04-21, 2020-04-23, and 2020-0426, dexamethasone was given as an antiallergic treatment, and $50 \mathrm{ml}$ of human albumin was given intravenously.

\section{Surgical treatment process}

The patient underwent right breast huge tumor resection on 2020-04-23 (Figure 3A). After the anesthesia took effect, routine disinfection, draping, and hand wrapping were performed. The right breast tumor occupied the entire breast, and the breast surface had ruptured about $7.0 \mathrm{~cm} \times 7.0 \mathrm{~cm}$. After disinfection, the entire breast was wrapped and fixed by a sterile bag. The distance from the tumor was greater than $3 \mathrm{~cm}$, including the nipple and areola. A horizontal circular 

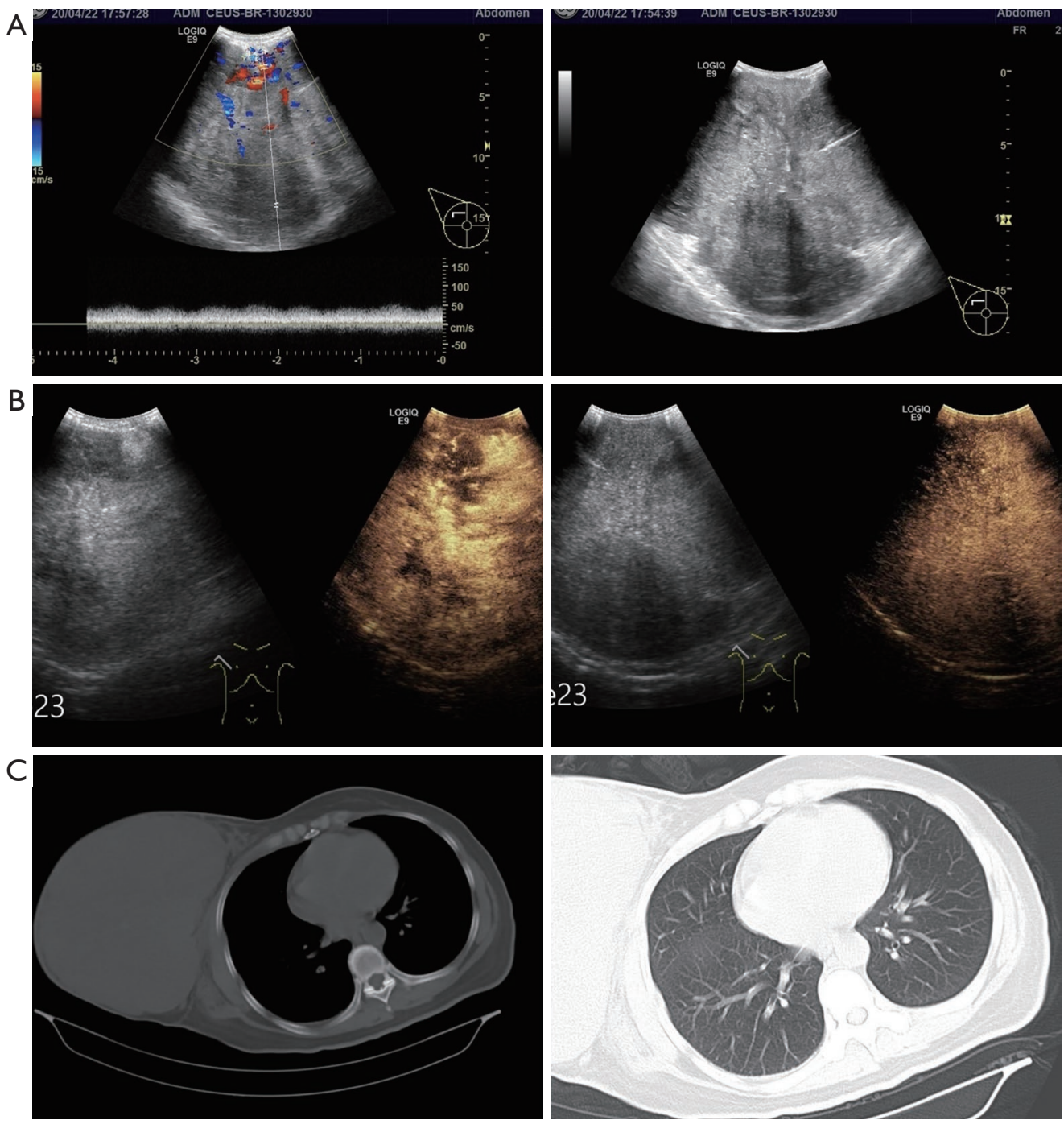

Figure 2 Imaging results. The tumor in B-Ultrasound (A) and Radiography (B) revealed abnormal shape of right breast, increase in volume, and BI-RADS:4C. CT imaging $(\mathrm{C})$ indicated the right breast is huge and consider the possibility of malignancy.

incision was made to cut the skin and subcutaneous tissue. The skin was freed with a high-frequency electric knife, up to the clavicle, down to $2 \mathrm{~cm}$ below the breast crease, inside to the middle of the breastbone, and outside the anterior axillary line. During the operation, the tumor had a rich blood supply, and the tumor was about $30 \mathrm{~cm} \times 25 \mathrm{~cm} \times$ $24 \mathrm{~cm}$ in size. The base of the tumor was partly attached to the pectoralis major fascia. The blood supply to the tumor was cut off, and the entire breast tissue and pectoralis major fascia were removed from the inside. The entire tumor tissue was carefully removed to ensure that no tumor tissue remained at the surgical edge. Retaining the pectoralis major and pectoralis minor, the specimen was separated from the anterior end of the latissimus dorsi muscle (Figure 3B).

The removed specimens were frozen sectioned during the operation (right breast and tumor) and showed fibroepithelial tumor, so we consider a borderline phyllodes tumor, whether there was a higher grade, paraffin after surgery. The lesion needed to be diagnosed with multiple pieces of paraffin. It could be seen after operation: a huge breast specimen tissue of the right breast and tumor was about $30 \mathrm{~cm} \times$ $25 \mathrm{~cm} \times 24 \mathrm{~cm}$ in size. Harbor in the breast, there is a huge tumor with size about $30 \mathrm{~cm} \times 23 \mathrm{~cm} \times 16 \mathrm{~cm}$. The surface of tumor was gray, red, and white. It seemed to have a leaflike structure (Figure 3B). The wound was rinsed with warm distilled water and the bleeding carefully stopped. After 

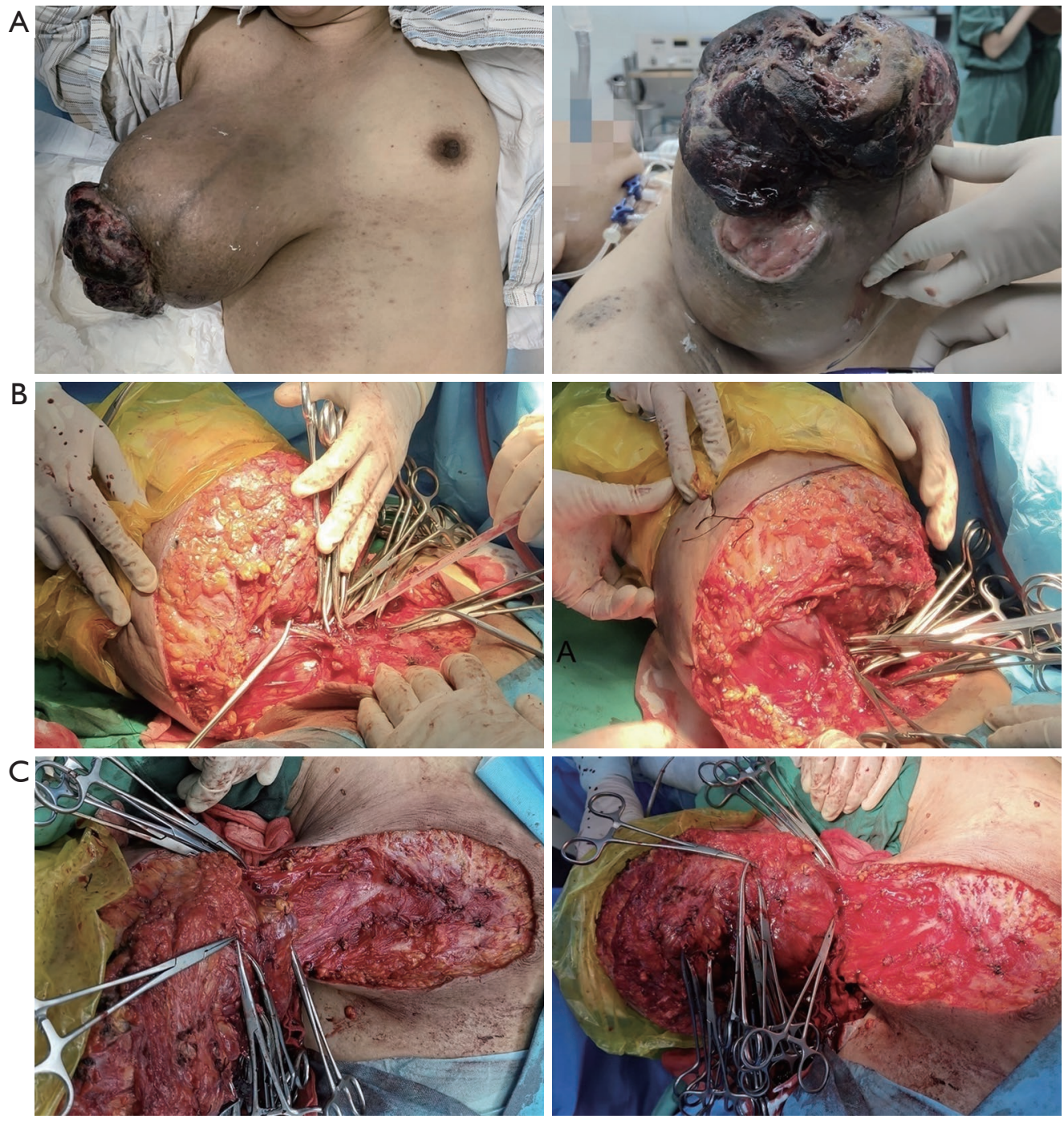

Figure 3 The operation process. Before the operation (A): When the patient entered the operating room, lying on the operating bed. Undergoing surgery (B): This patient underwent the right breast huge tumor radical resection.

confirming that there was no active bleeding, the wound is covered with hemostatic cotton to prevent further bleeding, and a drainage tube was placed on the inner side of the dry chest and under the armpits, connected to a disposable negative pressure continuous drainage device. After counting the number of pairs of gauze and instruments, the surgical port was closed with absorbable surgical sutures (imported fast forest), covered with sterile dressings, and the armpits were pressurized. The whole operation was smooth, and the anesthesia effect was good. The high-frequency electric knife and ultrasonic knife were used throughout the whole process. The vital signs of the patient were stable. The intraoperative infusion was $2,750 \mathrm{~mL}$, the bleeding was $600 \mathrm{~mL}$, and the blood transfusion was $6.0 \mathrm{U}$. After the operation, the tracheal intubation was brought back to the resuscitation room for observation. The patient returned to the ward safely after the operation, recovered well after the operation, and was discharged from the hospital once she was verified to be in a stable condition.

\section{Postoperative pathological diagnosis}

The patient's diagnosis was fibroepithelial tumor, in line with a borderline phyllodes tumor (Figure 4).

Figure $5 A$ shows the patient before surgery. Five months after the operation, the patient's surgical scar, about $15 \mathrm{~cm}$ 

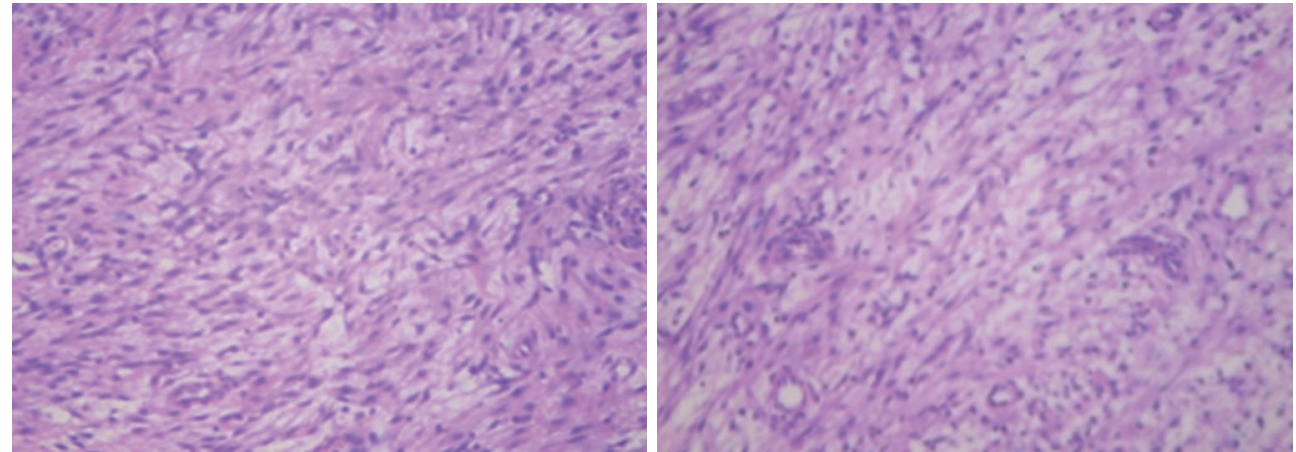

Figure 4 Histology showed a breast cancer (H\&E staining, ×200).
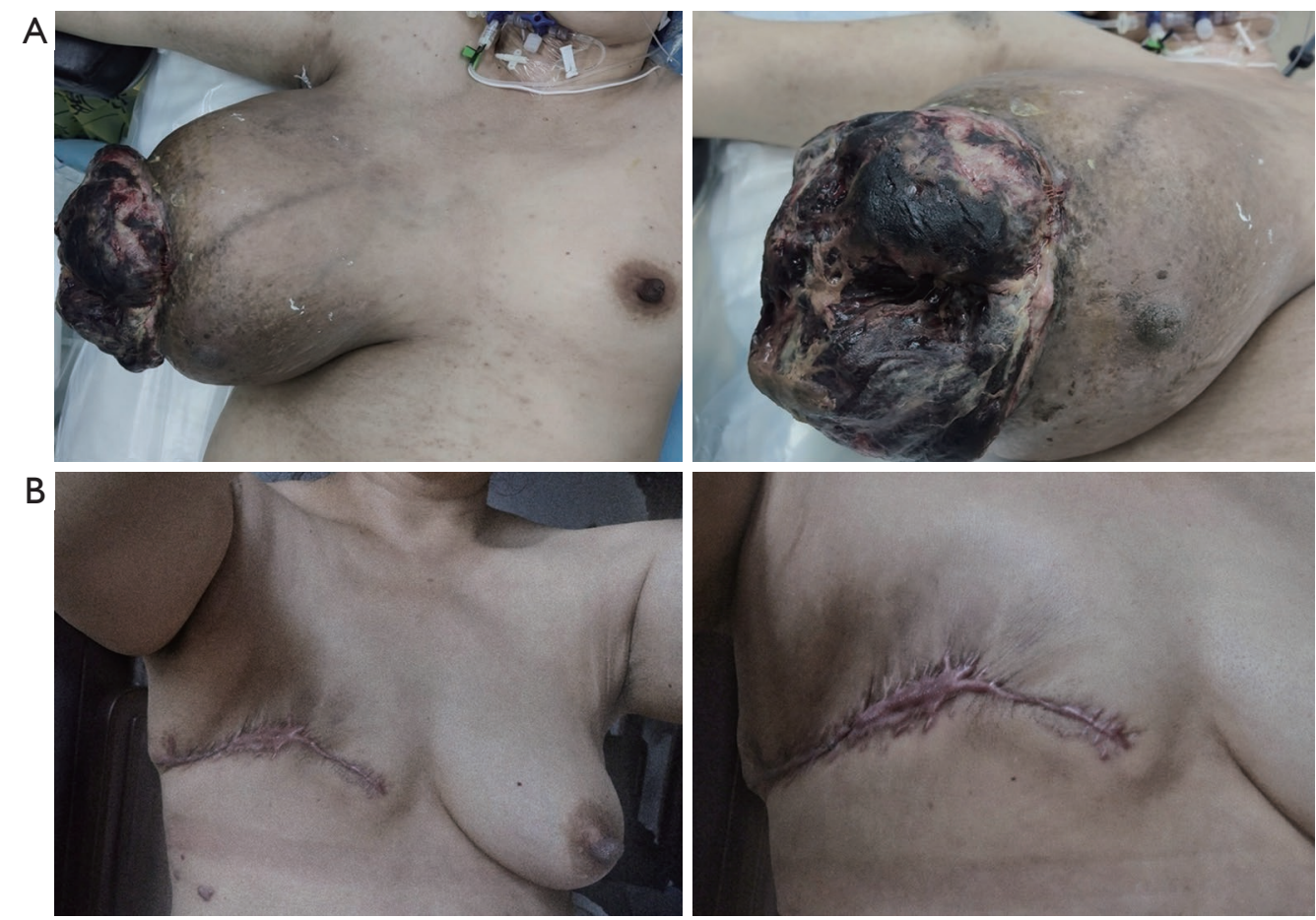

Figure 5 Comparison of patient's right breast before (A) and after (B) surgery.

long, is visible on her right front chest wall (Figure $5 B$ ). At the time of the reported case, the patient had been 4 months after surgery and was followed up for 6 months. Her condition was stable and remained no signs of clinical or imaging recurrence, and timely follow-up was carried out. The timeline of diagnosis and therapy is shown in Table 2.

\section{Discussion}

Demian et al. studied the radiotherapy of 12 patients with phyllodes tumors, which seemed to improve the 5 -year survival rate and reduce the local recurrence rate (13). However, Ossa et al. conducted a clinical study. Involving 77 patients, it showed no impact on survival (14). At present, in local recurrence or mastectomy, if the safety range is less than $10 \mathrm{~mm}$, radiotherapy is required $(14,15)$. Several chemotherapy regimens have been used without any benefit in terms of survival. Doxorubicin has been successfully used in a few studies for patients with local inoperable recurrence or metastasis $(16,17)$.

All clinical studies suggest that the extended tumor resection should be performed with a minimum safe 
Table 2 Organization of the case into a timeline

\begin{tabular}{|c|c|}
\hline Time & Treatment (T)/symptoms (S)/examination (E) \\
\hline Aug.2019 & $\begin{array}{l}\text { (T) Consciously the mass increased compared to the previous one, but did not get better after self-administration } \\
\text { (unknown), and later went to a hospital for breast B-ultrasound. It was recommended to puncture the diagnosis, but the } \\
\text { patient refused treatment }\end{array}$ \\
\hline Apr.20.2020 & (E) WBC:10.88×10\%/L (N: 3.5-9.5); HB:75 g/L (N: 115-150); ALB:31 g/L (N: 35-55) \\
\hline Apr.21.2020 & (T) Intravenous infusion of human albumin $50 \mathrm{~mL}$ \\
\hline Apr.22.2020 & (T) Intravenous infusion of suspended red blood cells $5.0 \mathrm{U}+$ plasma $200 \mathrm{~mL}$ \\
\hline Apr.28.2020 & 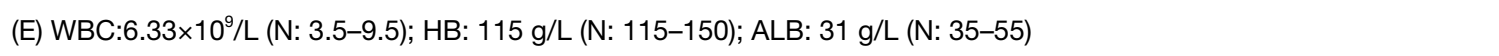 \\
\hline Apr.29.2020 & Discharged \\
\hline
\end{tabular}

WBC, leukocyte; HB, Hemoglobin; ALB, albumin.

distance of at least $1 \mathrm{~cm}(18,19)$. For large tumors larger than $5 \mathrm{~cm}$, mastectomy is recommended immediately (20). From benign borderline to malignant phyllodes tumors, the risk of local recurrence is significantly increased Mitochondria, tumor borders, increased stromal cells, stromal abnormalities, stromal overgrowth, tumor necrosis, type of surgery, and status of surgical margins may be risk factors for local recurrence $(21,22)$.

When the patient in this case study came to our hospital, the tumor was ulcerated and exuded due to prolonged illness. After consulting the related literature, there is found to be no relevant report on the relationship between borderline phyllodes tumor and anemia. We believe that it may be because the tumor burden is too large, leading to anemia. Rich blood supply and high nutritional requirements are the reasons for the increase in leukocyte (WBC) and the decrease in albumin (ALB), and hemoglobin (HB), after the patient's physical condition was adjusted quickly, surgical treatment was given in time. Because the tumor was too large and there was no normal breast tissue, the operation field was blurred during the operation, and separation was difficult. We removed the mass completely without destroying the normal tissue and structure. The treatment effect was obvious, no related adverse events occurred during or after the operation, the postoperative recovery was good, the patient was in stable condition and was discharged. Existing research data indicate that surgical treatment including breast-conserving surgery or mastectomy is main means of radical treatment of phyllodes tumors. However, according to a review involving 5,530 patients, the overall recurrence rate of these patients is high, at $19.1 \%$ (14). According to a study in the National Cancer Database of the Cancer Council of the American College of Surgeons, involving 3120 patients, adjuvant radiotherapy for phyllodes tumors was used in $19.5 \%$ of cases between 2008 and 2009 (9). Data from this large retrospective study showed that radiotherapy can prolong the time of local recurrence and reduce the rate of local recurrence, but it has no significant effect on survival. Another prospective study also discussed the effectiveness of radiotherapy for local disease control (23). However, few data have pointed out the relationship between radiotherapy and metastasis. A review of the available data shows that chemotherapy has a negligible effect in the treatment of phyllodes tumors. Due to lack of evidence, most clinicians avoid chemotherapy as a first-line treatment $(24,25)$. Thus far, only one prospective study involving 7 patients has shown that chemotherapy has little effect on survival (26). The sample size of other retrospective studies is too small to prove the efficacy of chemotherapy in the treatment of phyllodes tumors. In 
summary, due to our rapid and thorough treatment, good results have been achieved. The long-term effect will be further evaluated after 5 years. The patient was satisfied with our treatment.

At the same time, we can learn from this case that the treatment of borderline phyllodes tumor is mainly to remove the tumor completely without tumor remnants. Simple mastectomy is suitable for the treatment of giant phyllodes tumors.

\section{Acknowledgments}

The manuscript listed above was copy edited for proper English language at LetPub.

Funding: The present study was supported by the National Natural Science Foundation of China (grant no. 81960542 and 81960517), Science and Technology Project of Yunnan Provincial Science and Technology Department (grant no.202001AU070053 and 202001AU070093), Scientific Research Foundation of Yunnan Education Department (grant no. 2019J1288 and 2020J0198). Yunnan Health Training Project of High Level Talents (grant no. H-2019075).

\section{Footnote}

Reporting Checklist: The authors have completed the CARE reporting checklist. Available at: http://dx.doi.org/10.21037/ tcr-20-3461

Conflicts of Interest: All authors have completed the ICMJE uniform disclosure form (available at http://dx.doi. org/10.21037/tcr-20-3461). The authors have no conflicts of interest to declare.

Ethical Statement: The authors are accountable for all aspects of the work in ensuring that questions related to the accuracy or integrity of any part of the work are appropriately investigated and resolved. The study was approved by the People's committee of the Third Affiliated Hospital of Kunming Medical University (NO.: KY2019131). All procedures performed in studies involving human participants were in accordance with the ethical standards of the institutional and/or national research committee(s) and with the Declaration of Helsinki (as revised in 2013). Written informed consent was obtained from the patient.

Open Access Statement: This is an Open Access article distributed in accordance with the Creative Commons Attribution-NonCommercial-NoDerivs 4.0 International License (CC BY-NC-ND 4.0), which permits the noncommercial replication and distribution of the article with the strict proviso that no changes or edits are made and the original work is properly cited (including links to both the formal publication through the relevant DOI and the license). See: https://creativecommons.org/licenses/by-nc-nd/4.0/.

\section{References}

1. Rodrigues MF, Truong PT, McKevitt EC, et al. Phyllodes tumors of the breast: The British Columbia Cancer Agency experience. Cancer Radiother 2018;22:112-9.

2. Lu Y, Chen Y, Zhu L, et al. Local Recurrence of Benign, Borderline, and Malignant Phyllodes Tumors of the Breast: A Systematic Review and Meta-analysis. Ann Surg Oncol 2019;26:1263-75.

3. Co M, Chen C, Tsang JY, et al. Mammary phyllodes tumour: a 15-year multicentre clinical review. J Clin Pathol 2018;71:493-7.

4. Zhang Y, Kleer CG. Phyllodes Tumor of the Breast: Histopathologic Features, Differential Diagnosis, and Molecular/Genetic Updates. Arch Pathol Lab Med 2016;140:665-71.

5. Kalambo M, Adrada BE, Adeyefa MM, et al. Phyllodes Tumor of the Breast: Ultrasound-Pathology Correlation. AJR Am J Roentgenol 2018;210:W173-9.

6. Yii N, Read T, Tan CC, et al. Diagnosing phyllodes tumours of the breast: how successful are our current preoperative assessment modalities. ANZ J Surg 2018;88:988-92.

7. Ogunbiyi S, Perry A, Jakate K, et al. Phyllodes tumour of the breast and margins: How much is enough. Can J Surg 2019;62:E19-21.

8. Kim YJ, Kim K. Radiation therapy for malignant phyllodes tumor of the breast: An analysis of SEER data. Breast 2017;32:26-32.

9. Abdul Hamid S, Rahmat K, Ramli MT, et al. Radiopathological characteristics and outcomes of phyllodes tumor of the breast in Malaysian women. Medicine (Baltimore) 2018;97:e11412.

10. Graña López L, Vázquez Caruncho M, Villares AÁ. Percutaneous removal of benign phyllodes tumor of the breast: An alternative to surgery. Breast J 2018;24:1035-7.

11. Mitus JW, Blecharz P, Jakubowicz J, et al. Phyllodes tumors of the breast. The treatment results for 340 patients from a single cancer centre. Breast 2019;43:85-90. 
12. Semiglazov VV, Shu V, Tabagua TT, et al. Diagnosis and treatment of phylloides tumors of the breast. Vopr Onkol 2016;62:552-9.

13. Demian GA, Fayaz S, El-Sayed Eissa H, et al. Phyllodes tumors of the breast: Analysis of 35 cases from a single institution. J Egypt Natl Canc Inst 2016;28:243-8.

14. Ossa CA, Herazo F, Gil M, et al. Phyllodes tumor of the breast: a clinic-pathologic study of 77 cases in a Hispanic cohort. Colomb Med (Cali) 2015;46:104-8.

15. Toh YF, Cheah PL, Looi LM, et al. Phyllodes tumours of the breast: retrospective analysis of a University Hospital's experience. Malays J Pathol 2016;38:19-24.

16. Wada A, Hayashi N, Endo F, et al. Repeat recurrence and malignant transition of phyllodes tumors of the breast. Breast Cancer 2018;25:736-41.

17. Ganesh V, Drost L, Lee J, et al. A retrospective review of phyllodes tumours of the breast: A single institution experience. Breast 2018;38:52-7.

18. Sanchez AM, Franceschini G, Di Giorgio D, et al. Metastatic giant malignant phyllodes tumor of the breast. Breast J 2018;24:416-7.

19. Sevinç Aİ, Aksoy SÖ, Güray Durak M, et al. Is the extent of surgical resection important in patient outcome in benign and borderline phyllodes tumors of the breast. Turk J Med Sci 2018;48:28-33.

Cite this article as: Wang Q, Zheng $\mathrm{K}$, Zhang $\mathrm{L}$, Tan $\mathrm{M}$, Li H, Zhang H, Chen D, Li Z, Chuan Z, Wang X, Wang Y, Zhe L, Liu L, Liu D, Guo R, Tang S. The treatment process of an extremely rare giant borderline phyllodes tumor of breast: case report and literature review. Transl Cancer Res 2021;10(4): 1921-1929. doi: 10.21037/tcr-20-3461
20. Tremblay-LeMay R, Hogue JC, Provencher L, et al. How Wide Should Margins Be for Phyllodes Tumors of the Breast. Breast J 2017;23:315-22.

21. Moten AS, Goldberg AJ. Malignant Phyllodes Tumors of the Breast: Association Between Race, Clinical Features, and Outcomes. J Surg Res 2019;239:278-83.

22. Yogi V, Singh OP, Malviya A, et al. Effect of postoperative time for adjuvant radiotherapy in malignant phyllodes tumor: An institutional experience. J Cancer Res Ther 2018;14:1054-8.

23. Yabanoglu H, Colakoglu T, Aytac HO, et al. Comparison of Predictive Factors For the Diagnosis and Clinical Course of Phyllodes Tumours of the Breast. Acta Chir Belg 2015;115:27-32.

24. Chao X, Chen K, Zeng J, et al. Adjuvant radiotherapy and chemotherapy for patients with breast phyllodes tumors: a systematic review and meta-analysis. BMC Cancer 2019;19:372.

25. Urbaniak A, Jousheghany F, Yuan Y, et al. The response of phyllodes tumor of the breast to anticancer therapy: An in vitro and ex vivo study. Oncol Lett 2019;18:5097-106.

26. Ramakant P, Selvamani, Therese MM, et al. Metastatic Malignant Phyllodes Tumor of the Breast: An Aggressive Disease-Analysis of 7 Cases. Indian J Surg Oncol 2015;6:363-9. 